\title{
Increasing Safety and Efficacy of Suzuki Dynamic Fixation
}

ISSN: 2576-8875

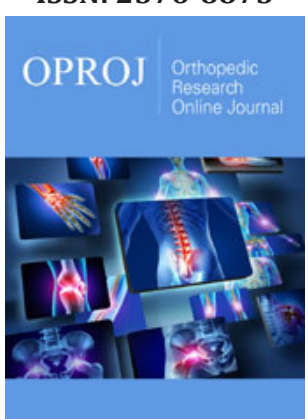

*1Corresponding author: Salim Al Lahham, Plastic surgeon, Hamad medical corporation, Qatar

Submission: 監 March 15, 2019

Published: 眥 March 19, 2019

Volume 5 - Issue 3

How to cite this article: Ahmed M M E, Salim A L, Ruba S, Talal A H. Increasing Safety and Efficacy of Suzuki Dynamic Fixation. Ortho Res Online J. 5(3). OPROJ.000612.2019.

DOI: 10.31031/OPROJ.2019.05.000612

Copyright@ Salim Al Lahham, This article is distributed under the terms of the Creative Commons Attribution 4.0 International License, which permits unrestricted use and redistribution provided that the original author and source are credited.

\author{
Ahmed Mokhtar Mahmoud Elbayer, Salim Al Lahham*, Ruba Sada and Talal Al \\ Hetmi \\ Plastic surgeon, Hamad medical corporation, Qatar
}

\begin{abstract}
Suzuki dynamic fixation is one of the excellent methods in management of pylon fractures and fracture dislocations of PIP joints in the fingers. The cost of this surgery is very cheap since it depends on K-Wires in creation of its framework. This technique is very effective in producing good Range of motion of the affected digit if was applied and maintained well. There are some complications that can negatively affect on the outcome especially sliding of the k-wires through their bone track which imbalance the traction and causes painful motion and can also causes pin track infection. Here we mention a simple modification which solve this issue and increase the safety and efficacy of Suzuki dynamic traction.
\end{abstract}

\section{Introduction}

Pylon fractures and fracture dislocations are not uncommon injuries of PIP joint of fingers especially the little and ring fingers during sport activities or construction work as well. These injuries are usually high energy type and associated with destruction of articular surface of the PIP joint which can cause stiff joint and consequently bad digit. There are many types of fixation for such fractures, but the best outcome is always seen with dynamic type of fixation which allows the patient to start range of motion activity soon after surgery and decrease the incidence of stiffness [1-3].

\section{Discussion}

The famous methods of management are Suzuki dynamic traction, volar plate arthroplasty and also hemi-hamate bone grafting. In our experience we found that Suzuki dynamic traction is an excellent way of management due to the following causes;

a) Cheap surgery, the K-wires are so cheap.

b) Minimal invasive (percutaneous approach)

c) Dynamic type of fixation (patient mobilize his finger from first day postop).

On the other way we found that $\mathrm{k}$ wire migration (sliding through the bone affects the whole balance of fixation and causes:

a. angulation of finger

b. painful motion

c. limited range of motion

d. higher incidence of pin track infection.

Here we describe our simple modification in the Suzuki frame which we used in 7 cases till the time of writing of this case report. Our main goal was to get balanced frame which does not lose its stability on the transverse plane. We used the rubber pieces from insulin injection to control the distance of each side of frame accurately. For the $\mathrm{K}$-wire passing through the 
head of proximal phalanx we used one and a half rubber pieces on each side and the wire was bended just at that distance [4].

For the distal wires we used one rubber piece on each side and got the wires bended at that distance (Figure1 \& 2). The tip of wires which was cut distally was coated with piece of rubber and dermabond to get securely fixed [5].

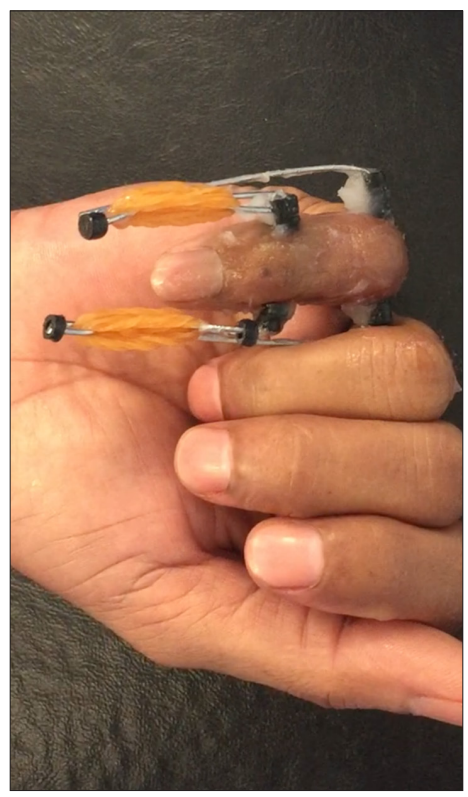

Figure 1:

\section{Figure 2:}

\section{Results}

The frame was kept for 4 weeks and weekly follow up was done by us and occupational therapists who frequently adjusted the springs to keep the desired traction [6]. We encountered no change of stability of the fame and the fixation was well maintained in the desired direction with no infection.

\section{Conclusion}

Our simple modification of Suzuki frame provides increased stability of the frame and good favorable outcome.

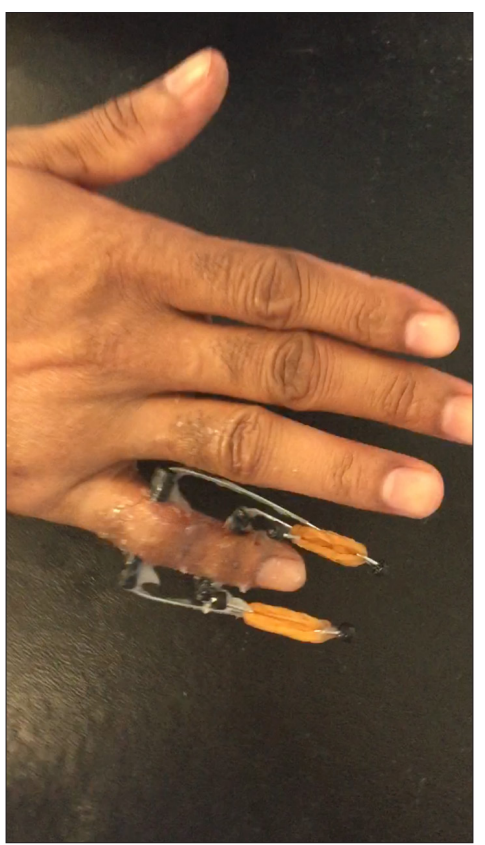

\section{References}

1. Nam SM, Park ES, Shin H, Jung SG, Kim YB (2010) Interphalangeal traction for comminuted fracture of middle phalanx fingers: case report. J Hand Surg Am 35(8): 1282-1285.

2. Richter M, Brüser P (2008) Long-term follow-up of fracture dislocations and comminuted fractures of the PIP joint treated with Suzuki's pin and rubber traction system. Handchir Mikrochir Plast Chir 40(5): 330-335.

3. Glickel SZ, Barron OA, Eaton RG (1999) Dislocations and ligament injuries in the digits. In: Green DP, Hotchkiss RN, Pederson C, (Eds.), Operative Hand Surgery, ( $4^{\text {th }}$ edn), Churchill Livingstone, New York, USA, pp. $772-808$. 
4. Liss FE, Green SM (1992) Capsular injuries of the proximal interphalangeal joint. Hand Clin 8(4): 755-768.

5. Minamikawa Y, Horii E, Amadio PC, Cooney WP, Linscheid RL, et al (1993) Stability and constraint of the proximal interphalangeal joint. J Hand Surg 18(2): 198-204
6. Hastings H II, Ernst JMJ (1993) Dynamic external fixation for fractures of the proximal interphalangeal joint. Hand Clin 9(4): 659-674.

For possible submissions Click below: 